PETERMANN, Vânia; FARIAS, Paulo Marcos de. Entre a soberania estatal e a economia: a reinvenção do judiciário como poder na atual fase da globalização. Revista Eletrônica Direito e Política, Programa de Pós-Graduação Stricto Sensu em Ciência Jurídica da UNIVALI, Itajaí, v.10, n.2, $1^{\circ}$ quadrimestre de 2015. Disponível em: www.univali.br/direitoepolitica - ISSN 1980-7791.

\title{
ENTRE A SOBERANIA ESTATAL E A ECONOMIA: A REINVENÇÃO DO JUDICIÁRIO COMO PODER NA ATUAL FASE DA GLOBALIZAÇÃO
}

\author{
BETWEEN THE STATE SOVEREIGNTY AND THE ECONOMY: THE \\ REINVENTION OF THE JUDICIARY HOW POWER IN THE ATUAL \\ GLOBALIZATION TIME
}

\author{
Vânia Petermann ${ }^{1}$ \\ Paulo Marcos de Farias ${ }^{2}$
}

SUMÁRIO: Introdução; 1 . A conformação do novo cenário mundial; 2. O papel do Estado nesse novo cenário mundial: a redefinição do conceito de soberania e a efetivação dos direitos fundamentais; 3 . A reinvenção do Judiciário como poder na atual Era da globalização; Considerações Finais; Referências das fontes citadas.

RESUMO: Se por um lado a expansão dos mercados e o agigantamento das corporações transnacionais coloca em xeque o conceito clássico da soberania estatal, de outro as conquistas sociais no campo dos direitos fundamentais tornam inviável (e insuficiente) a revigoração do Estado (neo)liberal ou minimalista. Analisar este quadro e a necessidade da reinvenção do Judiciário como poder é o objetivo deste estudo. A pesquisa foi elaborada mediante as técnicas do referente e consulta em obras impressas ou disponíveis na rede mundial de computadores. O método utilizado é o indutivo. O resultado da investigação reconhece o Judiciário enquanto instituição estratégica dotada de mecanismos para equacionar economia e direito, e consequentemente como poder propulsor do bem-estar e do desenvolvimento.

\footnotetext{
${ }^{1}$ Mestranda em Ciência Jurídica pela Universidade do Vale de Itajaí - UNIVALI. Juíza de direito do Juizado Especial Cível e Criminal da Trindade, Foro do Norte da Ilha, Florianópolis, Santa Catarina, Brasil. Professora no Curso de Formação Inicial I (Prática Forense) pela Academia Judicial do Tribunal de Justiça de Santa Catarina, Brasil, no concurso para ingresso na carreira da Magistratura; e-mail vania@tjsc.jus.br.

2 Mestrando em Ciência Jurídica pela Universidade do Vale de Itajaí - UNIVALI. Juiz de Direito da Vara do Tribunal do Júri convocado para atuar como Juiz Instrutor no Gabinete do Ministro Jorge Mussi desde 01/04/2014, no Superior Tribunal de Justiça, Brasília, Distrito Federal, Brasil. E-mail pmfarias@tjsc.jus.br.
} 
PETERMANN, Vânia; FARIAS, Paulo Marcos de. Entre a soberania estatal e a economia: a reinvenção do judiciário como poder na atual fase da globalização. Revista Eletrônica Direito e Política, Programa de Pós-Graduação Stricto Sensu em Ciência Jurídica da UNIVALI, Itajaí, v.10, n.2, $1^{\circ}$ quadrimestre de 2015. Disponível em: www.univali.br/direitoepolitica - ISSN 1980-7791.

Palavras-Chave: Globalização; Soberania; Economia; Direitos Fundamentais; Poder Judiciário.

ABSTRACT: If, on the one hand, the expansion of the markets and the enlargement of transnational corporations calls into question the classical concept of state sovereignty, on the other hand, the social achievements in the field of fundamental rights make it impossible (and insufficient) to reinvigorate the (neo)liberal or minimalist state. The purpose of this study is to analyze this framework and the need to reinvent the Judiciary as a source of power. The inductive method, the Referent, Category and Bibliographical research techniques, as well as the global network of computers were adopted. The research results recognize the Judiciary as an institution of strategic importance to weight law and economics, and therefore, as a power of well-being and development.

Keywords: Globalization; Sovereignty; Economics; Fundamental rights; Judiciary.

\section{INTRODUÇÃO}

Atualmente salta aos olhos o fenômeno da globalização: se no passado não era tão sentido, agora vem a passos largos pelas possibilidades das tecnologias da informação e da comunicação (internet) aliadas às facilidades do transporte internacional de pessoas e de bens. O desenvolvimento mundial com a abertura das fronteiras, todavia, mostra-se incapaz de resolver os problemas históricos da humanidade. A pobreza, a fome, a miséria, a incompreensão ao próximo (solidariedade) e a ignorância (ausência de informação formadora da cidadania) veem-se escancaradas pelos países mais pobres e ou em desenvolvimento. Assim, a globalização muitas vezes é vista muito mais com apreensão do que com entusiasmo.

Em um passado não muito anterior, aliás, registrou-se grave crise que assolou o mercado mundial, cujas consequências deveras desastrosas foram sentidas até em países desenvolvidos.

Dessas constatações ressai que nem só de progresso econômico se formam os anseios sociais. Em verdade, talvez antes disso, a humanidade realmente almeja é uma existência digna, sem violações aos direitos fundamentais. E a este 
PETERMANN, Vânia; FARIAS, Paulo Marcos de. Entre a soberania estatal e a economia: a reinvenção do judiciário como poder na atual fase da globalização. Revista Eletrônica Direito e Política, Programa de Pós-Graduação Stricto Sensu em Ciência Jurídica da UNIVALI, Itajaí, v.10, n.2, $1^{\circ}$ quadrimestre de 2015. Disponível em: www.univali.br/direitoepolitica - ISSN 1980-7791.

respeito, constata-se que as reivindicações se voltam precipuamente sobre o Estado.

Logo, se de um lado busca-se o progresso e o desenvolvimento econômico no planeta, de outro não se pode perder de mira a salvaguarda de mínimo existencial a todos os indivíduos.

Calcado nessa premissa, o objetivo do presente artigo é a investigação dos impactos da globalização na relação entre o Estado e a economia, donde ressai o Judiciário como Poder para equilibrar as duas forças, dado o seu papel de protetor e garantidor dos direitos fundamentais.

O método utilizado nesta pesquisa foi o indutivo, e a técnica adotada foi a da pesquisa bibliográfica em obras impressas e disponíveis na rede mundial de computadores.

No primeiro capítulo, abordar-se-á a complexidade da globalização, por se tratar de um fenômeno que pode ser analisado em vieses distintos. Ainda, serão apontadas as suas consequências para a conformação de novo cenário mundial, no qual o poder econômico se agiganta perante o político, vez que suplanta as fronteiras.

Já no segundo capítulo, o mote será a situação do Estado nessa nova contextura estabelecida em razão da globalização, analisando-se a perspectiva clássica, bem como o impasse relacionado à sua existência e aos seus limites em face do poder econômico. Em sequência, investigar-se-á a necessidade do repensar dos seus elementos, em especial a soberania.

Ainda, no terceiro capítulo, declinada a situação da economia e do Estado, será buscado o equilíbrio dessas forças a partir do estudo dos direitos fundamentais e do papel do Judiciário para a sua consagração, delineando-se o agigantamento deste como poder na Era da globalização.

Por fim, será apresentada a conclusão. 
PETERMANN, Vânia; FARIAS, Paulo Marcos de. Entre a soberania estatal e a economia: a reinvenção do judiciário como poder na atual fase da globalização. Revista Eletrônica Direito e Política, Programa de Pós-Graduação Stricto Sensu em Ciência Jurídica da UNIVALI, Itajaí, v.10, n.2, $1^{\circ}$ quadrimestre de 2015. Disponível em: www.univali.br/direitoepolitica - ISSN 1980-7791.

\section{A CONFORMAÇÃO DO NOVO CENÁRIO MUNDIAL}

A globalização é fenômeno deveras complexo, que pode ser comparado às ondas com avanços e retrocessos que podem durar até séculos, o qual se vê constantemente conectado à perspectiva econômica na ordem mundial.

A atual fase ou "onda" 3 da globalização tornou-se mais perceptível e acelerada com a internet e a facilitação dos transportes internacionais de bens e de pessoas. Com isso, extravasou a esfera do comércio, da produção e dos capitais, passando para outras formas de "intercâmbio mundial".

Nesse quadro, como adverte Anthony GIDDENS a ideia de globalização não se limita ao contexto econômico, vez que também está ligada às circunstâncias locais (micro) que repercutem no plano global (macro) e em sentido inverso:

A globalização trata efetivamente da transformação do espaço e do tempo. Eu a defino como ação a distância, e relaciono sua intensificação nos últimos anos ao surgimento da comunicação global instantânea e ao transporte de massa. [...] A globalização não é um processo único, mas uma mistura complexa de processos, que freqüentemente atua de maneira contraditória, produzindo conflitos, disjunções e novas formas de estratificação. ${ }^{4}$

Assim, a globalização nos dizeres de Roland ROBERTSON "se trata de um fenômeno que requer nitidamente aquilo que se chama convencionalmente tratamento interdisciplinar" 5 , vez que nele saltam interconexões e interdependências entre os diversos processos de ação e reação observados nas cadeias de relações e dependências que acabam se tornando mundiais.

\footnotetext{
${ }^{3}$ Para maiores aprofundamentos sobre as fases da globalização, cujo início não é unanimidade na doutrina (com a inclusão algumas vezes da expansão do império romano e o período das grandes navegações, perpassando pelas duas grandes guerras até a revolução da internet), sugere-se ler GUERRA, Sidney. A quarta onda globalizante e os desafios para o direito internacional. In Revista da Faculdade de Direito de Campos, Rio de Janeiro, Ano IV, n. 4 e Ano V, n. 5, 2003-2004. p. 341 a 357. Disponível em http://fdc.br/Arquivos/Mestrado/Revistas/Revista04e05/Docente/17.pdf Consulta em 29 de ago de 2014.

${ }^{4}$ GIDDENS, Anthony. Tradução de Álvaro Hattner. Para além da esquerda e da direita. O futuro da política radical. São Paulo: UNESP, 1996, p. 13. Título original: Beyond Left and Right: TheFuture of Radical Politics.

${ }^{5}$ ROBERTSON, Roland. Mapeamento da condição global: globalização como conceito central. In FEATHERSTONE, Mike (coord.) Cultura global - nacionalismo, globalização e modernidade. Tradução de Attílio Brunetta. Rio de Janeiro: Vozes, 1994. p. 26.
} 
PETERMANN, Vânia; FARIAS, Paulo Marcos de. Entre a soberania estatal e a economia: a reinvenção do judiciário como poder na atual fase da globalização. Revista Eletrônica Direito e Política, Programa de Pós-Graduação Stricto Sensu em Ciência Jurídica da UNIVALI, Itajaí, v.10, n.2, $1^{\circ}$ quadrimestre de 2015. Disponível em: www.univali.br/direitoepolitica - ISSN 1980-7791.

Logo, a globalização não entendida apenas como fenômeno econômico, deve ser analisada também sob o viés político, o qual envolve a aproximação e interconexão da grande maioria dos Estados soberanos em torno de objetivos e interesses comuns.

Também, sob a perspectiva social pode-se entender a globalização, que, palavras de Antony GIDDENS desta vez citado por Boaventura Sousa SANTOS, compreende-se como "a intensificação de relações sociais mundiais que une localidades distantes de tal modo que os acontecimentos locais são condicionados por eventos que acontecem a muitas milhas de distância e vice versa". 6

Registre-se que neste estudo interessa preponderantemente examinar o viés econômico da globalização, mas sem perder de mira os reflexos deste enfoque no político ${ }^{7}$ e social $^{8}$, os quais, como frisado, se interlaçam intimamente com o primeiro.

Por outro lado, cabe lembrar que o processo econômico da globalização intensifica relações mercantis a nível global, sendo ausente a polarização econômica, esta compreendida no sentido de que todos os agentes (Estado, governo e sociedade) devem participar do jogo econômico; bem como se verifica a crescente complexização e agigantamento do fenômeno econômico, a causar incertezas diuturnas sobre o rumo da economia dita "global" - como, por exemplo, os efeitos devastadores que movimentos internos potencialmente geram no mercado internacional ${ }^{9}$.

\footnotetext{
6 SANTOS, Boaventura Sousa. Os processos da globalização. Disponível em <http://www.eurozine.com/articles/2002-08-22-santos-pt.html>. Acesso em: 29 ago de 2013. Sem paginação.

7 Aqui o enfoque político se dá no entorno do poder estatal reduzido em face da abertura dos mercados e instalação de regras próprias nessas relações, privatizando parte das fontes do direito com esse movimento de internacionalização - nesse sentido MARTY, Mireille DELMAS. Tradução de Maria Ermantina de Almeida Prado Galvão. Por um direito comum. Martins Fontes: São Paulo, 2004, p. 46. Título no original: Pour um droit commun.

${ }^{8}$ Ou seja, direitos humanos versus interesses econômicos.

${ }^{9}$ Nesse aspecto, destaca-se a crise econômica mundial de 2008 - que gera efeitos até nossos dias -, em que uma 'bolha' no mercado imobiliário de alguns estados dos EUA causaram impacto em absolutamente todas as economias de mercado do globo.
} 
PETERMANN, Vânia; FARIAS, Paulo Marcos de. Entre a soberania estatal e a economia: a reinvenção do judiciário como poder na atual fase da globalização. Revista Eletrônica Direito e Política, Programa de Pós-Graduação Stricto Sensu em Ciência Jurídica da UNIVALI, Itajaí, v.10, n.2, $1^{\circ}$ quadrimestre de 2015. Disponível em: www.univali.br/direitoepolitica - ISSN 1980-7791.

No sentido econômico, ademais, diz-se que os traços principais desta nova economia mundial estão refletidos, segundo compreende-se da leitura de Boaventura Sousa SANTOS, nas seguintes explicações: a) economia subordinada pelo sistema financeiro e pelo investimento; b) produção flexibilizada e multilocal; c) redução a baixo custo os gastos com transporte; d) processos de produção flexíveis e multilocais; e) influência das tecnologias de informação e de comunicação; f) desregulação das economias nacionais; g) hegemonia das agências financeiras multilaterais como o FMI - Fundo Monetário Internacional e o Banco Mundial; h) emergência do capitalismo norte americano com privilégios nas relações comerciais com o Canadá, México e América Latina; i) a emergência do capitalismo japonês com iguais relações de privilégio comercial com Cingapura, Coreia do Sul, Taiwan e Hong Kong e os restante da Ásia; j) a emergência do capitalismo europeu fundado na União Europeia e relações privilegiadas desta com a Europa de Leste e com o Norte de África. ${ }^{10}$

Desse modo, nasceu o processo contemporâneo de "economização", pelo qual os paradigmas da ciência econômica (desregulamentação, organização supraestatal de empresas, etc.) passam a suplantar aqueles das demais ciências, notadamente a sociológica, a política e, sobretudo, a jurídica.

Assim, como acentua Boaventura Sousa SANTOS a sociedade civil, ao contrário do Estado, é "concebida como o domínio da vida econômica, das elações sociais espontâneas orientadas pelos interesses privados e particularísticos". ${ }^{11}$

Nessa linha, não é de surpreender contradição da ciência jurídica - seus princípios e regras - quando cede às demandas econômicas de corporações e empresas transnacionais. Como espécimes desse fenômeno, basta citar a sabida proibição, pela rede de fast-food McDonald's, a seus empregados de sindicalizarem, ou o jogo politiqueiro (e publicamente notório) consistente na guerra fiscal, travada entre Estados, para trazerem montadoras de veículos a

\footnotetext{
${ }^{10}$ SANTOS, Boaventura Sousa. Os processos da globalização. Sem paginação.

${ }^{11}$ SANTOS, Boaventura de Sousa. Pela mão de Alice. O social e o político na pós-modernidade. 2 ed. Cortez: São Paulo, 1195, p. 117.
} 
PETERMANN, Vânia; FARIAS, Paulo Marcos de. Entre a soberania estatal e a economia: a reinvenção do judiciário como poder na atual fase da globalização. Revista Eletrônica Direito e Política, Programa de Pós-Graduação Stricto Sensu em Ciência Jurídica da UNIVALI, Itajaí, v.10, n.2, $1^{\circ}$ quadrimestre de 2015. Disponível em: www.univali.br/direitoepolitica - ISSN 1980-7791.

seus territórios, muitas vezes em afronta, verbi gratia, às bases do direito tributário e do próprio princípio federativo.

Surge, portanto, uma classe capitalista transnacional, da qual as empresas multinacionais são as principais representantes. Vale destacar quase metade do produto industrial mundial é produzido por estas empresas, inclusive, percentual ainda maior é envolvido nas transações, no giro de capital pelas transnacionais. É certo que vantagens advêm desse processo - como o maior acesso a bens tecnológicos em escala global (i.e., telefonia, computação, automóveis, etc.). Entretanto, notadamente em países periféricos (usa-se a expressão "em desenvolvimento", de jaez eufemístico), nefastas conseqüencias sobrevém, em prejuízo de elevados direitos garantidos, aos cidadãos desses países, pelas respectivas leis e Constituições.

Destaca-se, também, o poder de bancos e dos fundos de investimentos, os quais, não raras vezes, utilizam-se de atividade especulativa para enriquecer a custa de indivíduos, ou pior, de nações inteiras, como é o recente caso da moratória argentina ${ }^{12}$.

Vive-se, assim, tempos de desenvolvimento econômico de vários países, o que, no entanto, não reduziu a desgraça da miséria e da fome mundial.

Permanecem, assim, hígidas as reinvindicações da sociedade no entorno dos direitos sociais que as modernas constituições Ihe conferiram.

Então o que podemos esperar desse quadro que se apresenta?

12 Thomas Griesa, magistrado americano que julgou um processo de reembolso de dívida do governo argentino com fundos de ação, considerou que a proposta de Buenos Aires para destravar pagamento das obrigações é "ilegal" e "inválida", decidindo, a seguir, a favor dos fundos especulativos que processaram a Argentina nos Estados Unidos para cobrar a dívida decorrente da moratória de 2001. Fonte: <http://g1.globo.com/economia/noticia/2014/08/argentina-acusa-juizamericano-de-impor-condicoes-ao-congresso.html>, acesso em 28/08/2014. 
PETERMANN, Vânia; FARIAS, Paulo Marcos de. Entre a soberania estatal e a economia: a reinvenção do judiciário como poder na atual fase da globalização. Revista Eletrônica Direito e Política, Programa de Pós-Graduação Stricto Sensu em Ciência Jurídica da UNIVALI, Itajaí, v.10, n.2, $1^{\circ}$ quadrimestre de 2015. Disponível em: www.univali.br/direitoepolitica - ISSN 1980-7791.

\section{O PAPEL DO ESTADO NESSE NOVO CENÁRIO MUNDIAL: A REDEFINIÇÃO DO CONCEITO DE SOBERANIA E A EFETIVAÇÃO DOS DIREITOS FUNDAMENTAIS}

Os Estados Nacionais, desde a sua formação no contexto mundial, passaram a se constituir como elemento fundamental na organização social e para a conformação e realização de direitos. Outrossim, são considerados os principais sujeitos da sociedade internacional, donde derivam as demais pessoas internacionais. ${ }^{13}$

Dessa constatação já se poderia justificar a inviabilidade da extinção ou da substituição dos Estados pelos entes que emergiram da globalização. No entanto, é inegável que o modelo clássico não se manteve incólume às transformações pelas quais o mundo tem passado especialmente a partir de meados do século $\mathrm{XX}$.

E é essa a reflexão que se propõe no presente tópico.

Os Estados Nacionais surgiram na Europa a partir do século XIII até os fins do século XVIII ou inícios do XIX, com a superação do sistema policêntrico e complexo típico do feudalismo. Essa alteração foi impulsionada pela necessidade de expansão comercial e consequentemente pela existência da unificação da organização politica e territorial para viabilizá-la. Por isso, diz-se que foi a economia que impulsionou o seu surgimento.

Nas palavras de Morgana Bellazi de Oliveira CARVALHO:

A imagem dos Estados Nacionais [...] favorecia o capitalismo na medida em que proporcionava segurança ao comerciante externo que quisesse ampliar seus negócios e seu mercado.

Com isso, surgiram, no século $\mathrm{XV}$, os Estados Nacionais, impulsionados por comerciantes e mercadores que reivindicavam uma nova ordem política e econômica capaz de viabilizar o desenvolvimento econômico interno do país e

13 CARVALHO, Morgana Bellazzi de Oliveira. A globalização e os desafios do Poder Judiciário no século XXI em prol da realização do bem-estar e do desenvolvimento. In: CONGRESSO NACIONAL DO CONPEDI, XVIII, 2009, São Paulo, Anais. Disponível em: <http://www.publicadireito.com.br/conpedi/manaus/arquivos/Anais/sao_paulo/2072.pdf>. Acesso em: 20 jul. 2014. p. 2093. 
PETERMANN, Vânia; FARIAS, Paulo Marcos de. Entre a soberania estatal e a economia: a reinvenção do judiciário como poder na atual fase da globalização. Revista Eletrônica Direito e Política, Programa de Pós-Graduação Stricto Sensu em Ciência Jurídica da UNIVALI, Itajaí, v.10, n.2, $1^{\circ}$ quadrimestre de 2015. Disponível em: www.univali.br/direitoepolitica - ISSN 1980-7791.

possibilitar a concorrência externa com outros países. Foi a vitória dos reis sobre os feudos. ${ }^{14}$

Mas o que representa e significa, de fato, o Estado?

Thomas Hobbes, ao enunciar a sua essência, assim expressou:

Uma Pessoa instituída, pelos atos de uma grande Multidão, mediante Pactos recíprocos uns com os outros, como Autora, de modo a poder usar a força e os meios de todos, da maneira que achar conveniente, para assegurar a Paz e a Defesa Comum. O titular dessa pessoa chama-se SOBERANO, e se diz que possui Poder Soberano. Todos os restantes são SÚDITOS. ${ }^{15}$

Bobbio, por sua vez, caracteriza o Estado nacional como um espaço "[...] territorial concentrado e unitário através da chamada racionalização da gestão do poder e da própria organização política imposta pela evolução das condições históricas materiais". ${ }^{16}$

E, para Max WEBER:

[...] o Estado é aquela comunidade humana que, dentro de determinado território - este o 'território', faz parte da qualidade característica - reclama para si (com êxito) o monopólio da coação física legítima, pois o específico da atualidade é que a todas as demais associações ou pessoas individuais somente se atribui o direito de exercer coação física na medida em que o Estado o permita. Este é considerado a única fonte do 'direito' de exercer coação. ${ }^{17}$

14 CARVALHO, Morgana Bellazzi de Oliveira. A globalização e os desafios do Poder Judiciário no século XXI em prol da realização do bem-estar e do desenvolvimento. p. 2092.

15 HOBBES, Thomas. Leviatã. Ou a matéria, forma e poder de um Estado eclesiástico e civil. Tradução de Rosina D’Angina. São Paulo: Ícone, 2008, 3a ed. Título original: Leviathan. p. 126. Grifo do autor.

16 BOBBIO, Norbeto; MATTEUCCI, Nicola, PASQUINO, Gianfranco. Tradução de Carmen C, Varriale et ai. Dicionário de Política. Vol. I. Brasília: UNB, 13a ed. 3a reimpressão, 2009, p. 426.Título original: Dizionario di política.

17 WEBER, Max. Tradução de Johannes Winckelmann. Economia e Sociedade. Vol. 1. Brasília: UNB, 1972, p. 525-526. Título original: Wirtschaft und Gesellschaft. 
PETERMANN, Vânia; FARIAS, Paulo Marcos de. Entre a soberania estatal e a economia: a reinvenção do judiciário como poder na atual fase da globalização. Revista Eletrônica Direito e Política, Programa de Pós-Graduação Stricto Sensu em Ciência Jurídica da UNIVALI, Itajaí, v.10, n.2, $1^{\circ}$ quadrimestre de 2015. Disponível em: www.univali.br/direitoepolitica - ISSN 1980-7791.

Ademais, conforme a previsão da Convenção Pan-Americana sobre Direitos e Deveres dos Estados de $1933^{18}$, diz-se que o Estado possui três elementos constitutivos, a saber: a) povo; b) território; c) soberania.

Por sua vez, de acordo com Darcy AZAMBUJA,

Povo é a população do Estado, considerada sob o aspecto puramente jurídico, é o grupo humano encarado na sua integração numa ordem estatal determinada, é o conjunto de indivíduos sujeitos às mesmas leis, são os súditos, os cidadãos de um mesmo Estado. Neste sentido, o elemento humano do Estado é sempre um povo, ainda que formado por diversas raças com interesses, ideais e aspirações diferentes. ${ }^{19}$

O território diz respeito à porção física do Estado, o extrato do globo em que está inserido, limite de sua atuação e porção donde advêm os recursos materiais para a sua existência. ${ }^{20}$

O terceiro e último, a soberania, envolve a autoafirmação, autodeterminação, a supremacia do Estado sobre os indivíduos que conformam sua população.

[...] a soberania designa, não o poder, mas uma qualidade do poder do Estado. A soberania é o grau supremo a que pode atingir esse poder, supremo no sentido de não reconhecer outro poder juridicamente superior a ele, nem igual a ele dentro do mesmo Estado. Quando se diz que o Estado é soberano, deve entender-se que, na esfera de sua autoridade, na competência que é chamado a exercer para realizar a sua finalidade, que é o bem público, ele representa um poder que não depende de nenhum outro poder, nem é igualado por qualquer outro dentro do seu território. ${ }^{21}$

18 O Decreto 1.570/1937 promulgou no Brasil as Convenções sobre direitos e deveres dos Estados e sobre Asilo político, assinadas em Montevidéo a 26 de dezembro de 1933, por ocasião da Sétima Conferencia internacional americana. Disponível em http://www.planalto.gov.br/ccivil_03/decreto/1930-1949/D1570.htm. Consulta em 29 ago 2014.

${ }^{19}$ AZAMBUJA, Darcy. Teoria Geral do Estado. Rio de Janeiro: Globo, 1969, p. 19.

${ }^{20}$ AZAMBUJA, Darcy. Teoria Geral do Estado, p. 36.

${ }^{21}$ AZAMBUJA, Darcy. Teoria Geral do Estado, p. 49-50. 
PETERMANN, Vânia; FARIAS, Paulo Marcos de. Entre a soberania estatal e a economia: a reinvenção do judiciário como poder na atual fase da globalização. Revista Eletrônica Direito e Política, Programa de Pós-Graduação Stricto Sensu em Ciência Jurídica da UNIVALI, Itajaí, v.10, n.2, $1^{\circ}$ quadrimestre de 2015. Disponível em: www.univali.br/direitoepolitica - ISSN 1980-7791.

Esta é a soberania sob o prisma interno. Externamente, a soberania se relaciona com igualdade, ou seja, significa que nas relações entre os Estados não existe subordinação nem dependência. ${ }^{22}$

A soberania - que apesar da divisão, especialmente para fins didáticos, mencionada, é uma só - encontra-se profundamente relacionada à ideia de poder, um poder político.

Não se olvida da complexidade da matéria e das várias teorias destinadas a explicar e a enunciar a soberania; todavia, no que interessa ao objetivo da presente pesquisa, constata-se que estreita ligação à noção de poder.

Ocorre que diante da contextura atual - delineada no item "1" do presente artigo - a complexidade da economia não permite a dissociação do poder exercido pela economia em face do Estado e da sua soberania. Este, aliás, é inegavelmente o elemento mais impactado pela globalização.

Ora, como visto, a globalização trouxe inúmeras consequências tanto no aspecto social, econômico, quanto político, que mitigaram os localismos e deram ensejo a problemas, soluções, diálogos, relações que superam os limites do território do Estado.

Além disso, o agigantamento do poderio econômico ganhou tamanha proporção que se tornou capaz de envolver o poder político.

Logo, há que se considerar que independência, supremacia e autoridade são componentes da soberania que demandam consideração compatível com essa nova realidade, mormente diante da expansão das corporações, de cunho transnacional.

Ademais,

O Estado já não pode mais almejar regular a sociedade civil nacional por meio de seus instrumentos jurídicos tradicionais, dada a crescente redução de seu poder de intervenção, controle e direção. Também já não pode deixar

${ }^{22}$ AZAMBUJA, Darcy. Teoria Geral do Estado, p. 49-50. 
PETERMANN, Vânia; FARIAS, Paulo Marcos de. Entre a soberania estatal e a economia: a reinvenção do judiciário como poder na atual fase da globalização. Revista Eletrônica Direito e Política, Programa de Pós-Graduação Stricto Sensu em Ciência Jurídica da UNIVALI, Itajaí, v.10, n.2, $1^{\circ}$ quadrimestre de 2015. Disponível em: www.univali.br/direitoepolitica - ISSN 1980-7791.

de compartilhar sua soberania com outras forças que transcendem o nível nacional. As funções do Estado-nação não desaparecem, mas assumem outras formas.

O que deve ocorrer, portanto, não é o fim da soberania e autonomia estatais, mas sim a revisão da função desses conceitos e adaptação aos novos parâmetros de convivência, cooperação internacional e formação de blocos econômicos. ${ }^{23}$

Noutro viés, há que se destacar que houve um fortalecimento das relações entre Estados, por meio de acordos político-econômicos interestatais como o NAFTA (North American Free Trade Agreement), o Mercosul (Mercado Comum do Sul) e a União Europeia. Esses novos atores econômicos, certo modo, surgiram como contraponto à diminuição da soberania em face da economia, pois representa revigorado controle estatal em demandas econômicas de mercados globais e transnacionais.

Em que pese o novo delinear assumido no contexto internacional, e até da importância dos blocos econômicos em relação aos Estados Nacionais considerados individualmente, a nova leitura mencionada não importa na extinção do Estado, tampouco na revigoração do (neo)liberalismo ${ }^{24}$.

É da sabença que o pensamento (neo)liberal não concorda com a participação política na economia. O (neo)liberalismo deseja o fator político cada vez menos participativo na economia de mercado. Mas, a total liberdade é basicamente impraticável, tendo em vista as diferenças sociais e econômicas apresentadas entre os países ricos, emergentes e pobres. O pensamento (neo)liberal prega a necessidade de não intervenção do Estado na economia, na medida em que ela

${ }^{23}$ CARVALHO, Morgana Bellazzi de Oliveira. A globalização e os desafios do Poder Judiciário no século XXI em prol da realização do bem-estar e do desenvolvimento. p. 2093.

24 Deve-se frisar a dificuldade de estabelecer um conceito fechado sem redundar numa visão reducionista, parte-se de uma perspectiva do liberalismo num sentido amplo, como liberdade para o mercado com a menor intervenção do estado possível O termo liberalismo é polissêmico, pelo que complexa é a enunciação de sentido unívoco. Consoante lecionam Bobbio, Matteucci e Pasquino: "A definição de Liberalismo como fenômeno histórico oferece dificuldades específicas, a menos que queiramos cair numa história paralela dos diversos Liberalismos ou descobrir um Liberalismo 'ecumênico', que não têm muito a ver com a história". BOBBIO, Norbeto; MATTEUCCI, Nicola, PASQUINO, Gianfranco. Tradução de Carmen C, Varriale et ai. Dicionário de Política. Vol. II, p. 686. 
PETERMANN, Vânia; FARIAS, Paulo Marcos de. Entre a soberania estatal e a economia: a reinvenção do judiciário como poder na atual fase da globalização. Revista Eletrônica Direito e Política, Programa de Pós-Graduação Stricto Sensu em Ciência Jurídica da UNIVALI, Itajaí, v.10, n.2, $1^{\circ}$ quadrimestre de 2015. Disponível em: www.univali.br/direitoepolitica - ISSN 1980-7791.

autorregula-se, argumentando que os efeitos imediatos de pobreza seriam circunstâncias temporárias.

Não é o que se tem observado no cenário mundial, entretanto!

Ademais, o pensamento (neo)liberal reconhece sua própria incapacidade, conformando-se com a ideia da manutenção de um Estado mínimo com intervenção subsidiária. Assim, com argumento em Marques NETO, Alexandre Morais da ROSA observa que:

Os sujeitos, segundo o modelo neoliberal, não podem depender do Estado que, pelo mercado e a seleção natural dos mais capazes, pode naturalizar as desigualdades sociais. ${ }^{25}$

Nesse prisma,

A Law and Economics convoca o Poder Judiciário a uma missão reformulada. Ao invés de se basear na tradição do direito de propriedade, ao Poder Judiciário cabe a função de maximização da riqueza, relendo, pois, o direito de propriedade, para o conceder a quem melhor puder o valorar dentro do critério econômico. ${ }^{26}$

Logo, não se pode admitir um Estado Mínimo em face dos direitos fundamentais expostos nas Constituições, porquanto à vista do que se vê é que o desenvolvimento econômico não tem naturalmente neutralizado os efeitos da miséria e da pobreza nos países pobres e emergentes. Obviamente que o viés econômico e desenvolvimentista devem ser tomados em consideração na atuação do Poder Judiciário, nada obstante, isso não serve de regra geral à presunção de prevalência frente a outros direitos sociais.

De fato, as conquistas sociais retratadas pela história mundial, bem como a experiência negativa quando se experimentou uma espécie de Estado mínimo levam à compreensão de que não se terá aceitação do retrocesso. Ou seja: a despeito de alianças econômicas, e do novo significado de soberania na atual Era da globalização, não se mostra cível que se estaria inclinando à volta do

\footnotetext{
25 ROSA, Alexandre Morais da; LINHARES, José Manuel Aroso. Diálogos com a Law \& Economics. Rio de Janeiro: Lumen Juris Editora, 2009. p. 43.

26 ROSA, Alexandre Morais da; LINHARES, José Manuel Aroso. Diálogos com a Law \& Economics, p. 72.
} 
PETERMANN, Vânia; FARIAS, Paulo Marcos de. Entre a soberania estatal e a economia: a reinvenção do judiciário como poder na atual fase da globalização. Revista Eletrônica Direito e Política, Programa de Pós-Graduação Stricto Sensu em Ciência Jurídica da UNIVALI, Itajaí, v.10, n.2, $1^{\circ}$ quadrimestre de 2015. Disponível em: www.univali.br/direitoepolitica - ISSN 1980-7791.

(neo)liberalismo em que não haveria resguardo de qualquer direito fundamental e em face do avanço econômico.

Com efeito, como adverte Norberto BOBBIO:

Se a globalização de mercados está acabando com a idéia tradicional de Estado-nação, deve-se fazer uma recomposição da idéia de Estado e de seus objetivos. Tal há de se dar. assim, em tomo dos direitos humanos, voltandose para uma soberania de um Estado garantidor do ser humano, garantidor das heterogeneidades e das possibilidades econômico-sociais de que cada um e todos possam desenvolver as suas singularidades. ${ }^{27}$

Nessa esteira, é de relevância a universalização de direitos humanos e sociais, seja nos tempos das Constituições Mexicanas de 1917 e de Weimar de 1919, como nas mais recentes pós nazifascimo, a constituir barreira ao avanço desenfreado da ditadura "economicista" na sociedade e nas soberanias nacionais.

Com efeito, o caráter universal dos direitos sociais - que, segundo Norberto BOBBIO $^{28}$ constituem prestação positiva do Estado -, a nível global, criou uma espécie de blindagem contra o poderio econômico.

E na medida em que se cuida da principal instituição para salvaguarda dos direitos fundamentais, mormente diante do fenômeno do constitucionalismo, o Judiciário se mostra como o Poder que pode equilibrar essas forças (economia e Estado).

\section{A REINVENÇÃo do JUdiciÁRIO COMO PODER NA ATUAL ERA DA GLOBALIZAÇÃO}

O Estado Democrático de Direito ${ }^{29}$ marca-se pelo abandono à ideia do Estado (neo)liberal, superando o Estado Social, "impondo à ordem jurídica e à atividade estatal um conteúdo utópico de transformação da realidade ${ }^{\prime 30}$.

27 BOBBIO, Norberto. Tradução de Carlos Nelson Coutinho. A Era dos direitos. 13a tiragem. São Paulo: 2004, p. 122. Título original: L'età dei Diritti.

${ }^{28}$ BOBBIO, Norberto. Tradução de Carlos Nelson Coutinho. A Era dos direitos, p. 6. 
PETERMANN, Vânia; FARIAS, Paulo Marcos de. Entre a soberania estatal e a economia: a reinvenção do judiciário como poder na atual fase da globalização. Revista Eletrônica Direito e Política, Programa de Pós-Graduação Stricto Sensu em Ciência Jurídica da UNIVALI, Itajaí, v.10, n.2, $1^{\circ}$ quadrimestre de 2015. Disponível em: www.univali.br/direitoepolitica - ISSN 1980-7791.

Esse é o modelo prevalente atualmente. E em se tratando de transformação da realidade, é inegável que os direitos humanos representam uma das maiores conquistas da história da humanidade.

Dentre as várias perspectivas em que podem ser conceituados, na visão aqui adotada, são compreendidos como:

[...] conjunto de valores históricos básicos e fundamentais, que dizem respeito à vida digna jurídico-político-psíquicofísico-econômica e afetiva dos seres humanos e de seu habitat, tanto daqueles do presente quanto daqueles do porvir, surgem sempre como condição fundante da vida, impondo aos agentes político-jurídico-econômico-sociais a tarefa de agirem no sentido de permitir e viabilizar que a todos seja consignada a possibilidade de usufruí-los em benefício próprio e comum ao mesmo tempo. ${ }^{31}$

A positivação desses direitos fundamentais decorre de processos luta, os quais são classificados pela doutrina como dimensões.

Os direitos de primeira dimensão tratam das liberdades negativas, ou seja, os direitos de liberdade, cuja conquista se deveu ao combate ao absolutismo Estatal, notadamente nas revoluções burguesas.

Por sua vez, os de segunda dimensão respeitam às liberdades positivas, ou aos chamados direitos sociais. Eles envolvem prestações positivas pelo Estado, condizentes em políticas públicas. Em especial, surgiram por ocasião da

29 São princípios do Estado Democrático de Direito, segundo Norberto BOBBIO: A Constitucionalidade: vinculação do Estado Democrático de Direito a uma Constituição como instrumento básico de garantia jurídica; B - Organização Democrática da Sociedade; C - Sistema de direitos fundamentais individuais e coletivos, seja como Estado de distância, porque os direitos fundamentais asseguram ao homem uma autonomia perante os poderes públicos, seja como um Estado antropologicamente amigo, pois respeita a dignidade da pessoa humana e empenha-se na defesa e garantia da liberdade, da justiça e da solidariedade; D - Justiça Social como mecanismos corretivos das desigualdades; E - Igualdade não apenas como possibilidade formal, mas, também, como articulação de uma sociedade justa; F - Divisão de Poderes ou de Funções; G - Legalidade que aparece como medida do direito, isto é, através de um meio de ordenação racional, vinculativamente prescritivo, de regras, formas e procedimentos que excluem o arbítrio e a prepotência; H - Segurança e Certeza Jurídicas. BOBBIO, Norberto. Tradução: Carlos Nelson Coutinho. A Era dos direitos, p. 122.

30 MORAIS, José Luis Bolzan de. Diretos humanos, Estado e globalização. Direitos humanos e globalização: fundamentos e possibilidades desde a teoria crítica, p. 132.

31 MORAIS, José Luis Bolzan de. Diretos humanos, Estado e globalização. Direitos humanos e globalização: fundamentos e possibilidades desde a teoria crítica, p. 131. 
PETERMANN, Vânia; FARIAS, Paulo Marcos de. Entre a soberania estatal e a economia: a reinvenção do judiciário como poder na atual fase da globalização. Revista Eletrônica Direito e Política, Programa de Pós-Graduação Stricto Sensu em Ciência Jurídica da UNIVALI, Itajaí, v.10, n.2, $1^{\circ}$ quadrimestre de 2015. Disponível em: www.univali.br/direitoepolitica - ISSN 1980-7791.

Revolução Industrial e têm na Constituição de Weimer (1919), da Alemanha, bem como na do México (1917) como importantes documentos.

Como adverte Norberto BOBBIO, são os direitos mais violados hodiernamente:

Já a maior parte dos direitos sociais, os chamados direitos de segunda geração, que são exibidos brilhantemente em todas as declarações nacionais e intemacionais, permaneceu no papel. (...) A única coisa que até agora se pode dizer é que são expressão de aspirações ideais, às quais o nome de "direitos" serve unicamente para atribuir um título de nobreza. Proclamar o direito dos indivíduos, não importa em que parte do mundo se encontrem (os direitos do homem são por si mesmos universais), de viver num mundo não poluído não significa mais do que expressar a aspiração a obter uma futura legislação que imponha limites ao uso de substâncias poluentes. Mas uma coisa é proclamar esse direito, outra é desfrutá-lo efetivamente. (...) A linguagem dos direitos tem indubitavelmente uma grande função prática, que é emprestar uma força particular às reivindicações dos movimentos que demandam para si e para os outros a satisfação de novos carecimentos materiais e morais; mas ela se toma enganadora se obscurecer ou ocultar a diferença entre o direito reivindicado e o direito reconhecido e protegido. Não se poderia explicar a contradição entre a literatura que faz a apologia da era dos direitos e aquela que denuncia a massa dos "sem-direitos". Mas os direitos de que fala a primeira são somente os proclamados nas instituições internacionais e nos congressos, enquanto os direitos de que fala a segunda são aqueles que a esmagadora maioria da humanidade não possui de fato (ainda que sejam solene e repetidamente proclamados $)^{32}$.

Por fim, os chamados direitos de terceira dimensão objetivam aos princípios de fraternidade e solidariedade, tendo em mira a proteção em especial dos direitos coletivos e difusos. Têm alicerce na época da expansão tecnológica, e sua efetivação pede atuação na esfera mundial, dada a superação das fronteiras pelas questões albergadas por esse direito, como a ambiental, a comunicação, a paz, e também o acesso à justiça ${ }^{33}$.

\footnotetext{
32 BOBBIO, Norberto. Tradução de Carlos Nelson Coutinho. A Era dos direitos, p. 9.

33 Para maior aprofundamento na temática das dimensões dos direitos fundamentais, sugere-se: SARLET, Ingo Wolfgang. A eficácia dos Direitos Fundamentais: uma teoria geral dos direitos
} 
PETERMANN, Vânia; FARIAS, Paulo Marcos de. Entre a soberania estatal e a economia: a reinvenção do judiciário como poder na atual fase da globalização. Revista Eletrônica Direito e Política, Programa de Pós-Graduação Stricto Sensu em Ciência Jurídica da UNIVALI, Itajaí, v.10, n.2, $1^{\circ}$ quadrimestre de 2015. Disponível em: www.univali.br/direitoepolitica - ISSN 1980-7791.

Alerta-se que, malgrado seja possível delinear devir histórico dos direitos fundamentais em período antecedente ${ }^{34}$, a previsão no texto das Constituições, além de originar a problemática das dimensões, demarcou a transição do Estado Liberal (Estado formal de Direito) para o moderno Estado de Direito (Estado social e democrático [material] de Direito), alterando sobremaneira as relações do Estado com a sociedade, e daqueles com a economia.

Noutros termos:

Somente a partir do reconhecimento e da consagração dos direitos fundamentais pelas primeiras Constituições é que assume relevo a problemática das assim denominadas 'gerações' (ou dimensões) dos direitos fundamentais, visto que umbilicalmente vinculada às transformações geradas pelo reconhecimento de novas necessidades básicas, de modo especial em virtude da evolução do Estado Liberal (Estado formal de Direito) para o moderno Estado de Direito (Estado social e democrático [material] de Direito), bem como pelas mutações decorrentes do processo de industrialização e seus reflexos, pelo impacto tecnológico e científico, pelo processo de descolonialização e tantos outros fatores direta ou indiretamente relevantes nesse contexto e que poderiam ser considerados ${ }^{35}$.

Dessa forma, "[...] o Estado constitucional determinado pelos direitos fundamentais assumiu feições de Estado ideal, cuja concretização passou a ser tarefa permanente" ${ }^{\prime 36}$.

E é nesse ponto que se centra a grande questão relacionada aos direitos fundamentais: a sua efetivação.

fundamentais na perspectiva constitucional. 11 ed. rev e atual. Porto Alegre: Livraria do Advogado Editora, 2012. p. 36-62.

34"Sintetizando o devir histórico dos direitos fundamentais até o seu reconhecimento nas primeiras Constituições escritas, K. Stern, conhecido mestre de Colônia, destaca três etapas: a) uma préhistória, que se estende até o século XVI; b) uma fase intermediária, que corresponde ao período de elaboração da doutrina jusnaturalista e da afirmação dos direitos naturais do homem; c) fase de constitucionalização, iniciada em 1776, com as sucessivas declarações de direitos dos novos Estados americanos". (SARLET, Ingo Wolfgang. A eficácia dos Direitos Fundamentais: uma teoria geral dos direitos fundamentais na perspectiva constitucional, p. 37)

35 SARLET, Ingo Wolfgang. A eficácia dos Direitos Fundamentais: uma teoria geral dos direitos fundamentais na perspectiva constitucional, p. 36-37.

${ }^{36}$ SARLET, Ingo Wolfgang. A eficácia dos Direitos Fundamentais: uma teoria geral dos direitos fundamentais na perspectiva constitucional, p. 59. 
PETERMANN, Vânia; FARIAS, Paulo Marcos de. Entre a soberania estatal e a economia: a reinvenção do judiciário como poder na atual fase da globalização. Revista Eletrônica Direito e Política, Programa de Pós-Graduação Stricto Sensu em Ciência Jurídica da UNIVALI, Itajaí, v.10, n.2, $1^{\circ}$ quadrimestre de 2015. Disponível em: www.univali.br/direitoepolitica - ISSN 1980-7791.

Ora, o moderno constitucionalismo reclama poderes que garantam os estatuídos pelas Cartas de cada país, sendo que, em havendo violação tanto pelo ente estatal quanto privado, há que se ter mecanismo ou instituição ao qual o cidadão possa recorrer. Pelo sistema prevalente, essa incumbência foi posta ao Poder Judiciário.

Nesse contexto, o constitucionalismo ofereceu mudanças estruturais nas funções do Poder Judiciário, ao que passou o Estado Democrático de Direito a se chamar de Estado Constitucional de Direito, agora alicerçado sob outras perspectivas: supremacia da Constituição, interdependência dos poderes; e dimensão objetiva dos direitos fundamentais ${ }^{37}$.

Assim, os direitos fundamentais ingressaram na seara dos valores do Estado e, via reflexa, a intervenção do Judiciário foi abraçada por esta mudança com a possibilidade de intervenção à proteção dos direitos fundamentais e o controle de constitucionalidade.

Teoricamente falando, [...] a adoção, no Brasil, do modelo norte-americano, não tão supreendentemente, conduziu o Judiciário, na sua evolução histórica, a desempenhar um papel diferenciado (mais 'ativo', como se dirá) na realização efetiva da Constituição, especialmente desde que se abandonou o modelo do Constitucionalismo moderno (norteamericano) liberal por um constitucionalismo social, mantendo, contudo, o mesmo modelo de defesa da Constituição quanto aos órgãos habilitados a realizar essa defesa ${ }^{38}$.

Já em 1952 Antonie GARAPON discorreu sobre a ampliação dos poderes do Judiciário, apresentando-o como instância de resgate dos ideais da justiça, o guardião dos promessas não cumpridas. Explica o jurista francês que:

O sucesso da justiça é inversamente proporcional ao descrédito que afeta as instituições políticas clássicas,

\footnotetext{
${ }^{37}$ SARLET, Ingo Wolfgang. A eficácia dos Direitos Fundamentais: uma teoria geral dos direitos fundamentais na perspectiva constitucional, p. 58-62.

${ }^{38}$ TAVARES, André Ramos. Justiça Constitucional e Direitos sociais no Brasil. In: FRANCISCO, José Carlos (Coord.). Neoconstitucionalismo e atividade jurisdicional: do passivismo ao ativismo judicial. Belo Horizonte-MG: Del Rey Editora, 2012. p. 143.
} 
PETERMANN, Vânia; FARIAS, Paulo Marcos de. Entre a soberania estatal e a economia: a reinvenção do judiciário como poder na atual fase da globalização. Revista Eletrônica Direito e Política, Programa de Pós-Graduação Stricto Sensu em Ciência Jurídica da UNIVALI, Itajaí, v.10, n.2, $1^{\circ}$ quadrimestre de 2015. Disponível em: www.univali.br/direitoepolitica - ISSN 1980-7791.

causado pela crise de desinteresse e pela perda do espírito público ${ }^{39}$.

Assim, "O direito não é mais o instrumento de conservação social, porém de sua contestação: ele se coloca então como a fonte de uma sociedade que se constitui na busca de si mesma". 40

Mauro CAPPELLETI, nesse contexto, informa o Poder Judiciário como o terceiro gigante (ao lado de Executivo e do Legislativo), o qual, na sua independência, é capaz de resistir às violações de direitos constitucionais ${ }^{41}$.

Consoante sustenta Edihermes Marques COELHO:

O fato é que o Poder Judiciário é, nesse contexto, um Poder estatal sui generis, devido às funções que potencialmente pode exercer frente à população e frente aos outros Poderes estatais. Frente à população estão todas as possibilidades de uma atuação respeitosa e efetivadora dos direitos humanos.

Frente aos outros Poderes estatais, salienta-se a potencialidade do Judiciário para atuar como fiscal e censor das atuações institucionais, no sentido de que estas não afrontem os valores superiores do sistema jurídico (especialmente aqueles consagrados constitucionalmente) ${ }^{42}$.

Insiste-se que o Direito e, via de consequência, o Poder Judiciário, não podem solucionar todos os problemas econômicos, políticos e sociais, especialmente em face da impossibilidade de substituir as atribuições dos outros poderes. Num modelo de tripartição de poderes ao Executivo incumbem a administração e a execução das políticas públicas; ao Legislativo, a edição de normas.

\footnotetext{
${ }^{39}$ GARAPON, Antoine. Tradução de Maria Luiza de Carvalho. O Juiz e a democracia. O guardião das promessas. Rio de Janeiro: REVAN, 2001, p. 48. Título original: Le gardien dess promesses.

${ }^{40}$ GARAPON, Antoine. Tradução: Maria Luiza de Carvalho. O Juiz e a democracia. O guardião das promessas, p. 50

${ }^{41}$ CAPPELLETTI, Mauro. Juízes Legisladores? Porto Alegre: Sérgio Anônio Fabris Editor, 1993, p. 107. Título original: Giudici Legislatori?

42 COELHO, Edihermes Marques. Os direitos fundamentais em face da globalização de mercados e o garantismo como referência jurídica necessária. Tese de doutoramento. 2002. Disponível em: <https://repositorio.ufsc.br/handle/123456789/82613>. Acesso em 20 de ago de 2014, p. 147.
} 
PETERMANN, Vânia; FARIAS, Paulo Marcos de. Entre a soberania estatal e a economia: a reinvenção do judiciário como poder na atual fase da globalização. Revista Eletrônica Direito e Política, Programa de Pós-Graduação Stricto Sensu em Ciência Jurídica da UNIVALI, Itajaí, v.10, n.2, $1^{\circ}$ quadrimestre de 2015. Disponível em: www.univali.br/direitoepolitica - ISSN 1980-7791.

No entanto, dada a posição central no quadro protetivo e realizador dos direitos fundamentais, para as hipóteses de inércia e/ou violação, a atuação é imperiosa em face da própria estrutura do sistema.

Realmente, não se pode olvidar que o aparecimento e o
florescimento da Justiça constitucional acabam ocorrendo
como uma alternativa ao modelo legalista, que entra em
crise no início do século XX, e como uma resposta aos
abusos ocorridos especialmente após a II Grande Guerra
mundial. Mas não apenas isso. É também uma resposta à
inércia dos 'poderes' que tradicionalmente eram
considerados como as únicas instâncias deliberativas em
termos de prestações e serviços estatais a serem oferecidos.
Em recente entrevista, um dos juízes do Supremo Tribunal
brasileiro considerou justamente que o Judiciário supre
omissões inconstitucionais do Estado, quando o Estado se
omite ou retarda excessivamente o cumprimento de suas
obrigações ${ }^{43}$.

Registre-se que, especialmente nas situações em que os direitos fundamentais vão de encontro, total ou parcialmente, a interesses econômicos, o Poder Judiciário é chamado a instrumentalizar a diminuição desses conflitos, engrandecendo a construção de modelos de convivência fundados em direitos humanos:

Os Estados, ainda que ciosos de sua autonomia, não querem abrir mão dos benefícios trazidos pelo livre comércio e pelo capital estrangeiro. Por isso, tentam equilibrar esses dois desejos, abrindo suas fronteiras ao comércio e aos investimentos, e procurando regular a economia quando 0 crêem necessário - mas a lentidão de seus processos políticos faz que inevitavelmente tenham de se curvar à vontade do mercado ${ }^{44}$.

Ademais, recorde-se que políticas possíveis em outros momentos da vida da humanidade não o são nessa situação de ambiguidade de vontades. Assim, pode-se concluir que o mercado de capital global acaba disciplinando os

\footnotetext{
${ }^{43}$ TAVARES, André Ramos. Justiça Constitucional e Direitos sociais no Brasil. In: FRANCISCO, José Carlos (Coord.). Neoconstitucionalismo e atividade jurisdicional: do passivismo ao ativismo judicial, p. 146.
}

${ }^{44}$ MATIAS, Eduardo Felipe. A Humanidade e suas fronteiras. São Paulo: Paz e Terra, 2005. p. 186. 
PETERMANN, Vânia; FARIAS, Paulo Marcos de. Entre a soberania estatal e a economia: a reinvenção do judiciário como poder na atual fase da globalização. Revista Eletrônica Direito e Política, Programa de Pós-Graduação Stricto Sensu em Ciência Jurídica da UNIVALI, Itajaí, v.10, n.2, $1^{\circ}$ quadrimestre de 2015. Disponível em: www.univali.br/direitoepolitica - ISSN 1980-7791.

governos nacionais. Nesse quadro, os países pobres e/ou em desenvolvimento, sabidamente mais vulneráveis, são os que mais sofrem com isso.

Citam-se, a título ilustrativo, as sociedades empresariais transnacionais que operam de maneira discriminatória em relação aos países que melhor se adaptam às suas características. E no "jogo" do desenvolvimento, acabam forçando esses países a compatibilizarem cada vez mais suas políticas econômicas em prol dos interesses das empresas. Cabe lembrar, ainda a título de exemplo, a influência das taxas de juros como único instrumento econômico à disposição dos governos. Esses, por seu turno dependem do "risco país" definido internacionalmente, o que demonstra a diminuição da soberania econômica estatal.

Existe, verdadeira "lei de mercado" imposta aos Estados carentes de recursos, que buscam atrair o capital transnacional flexibilizando seu direito interno e afastando-se da ética, substituindo o direito estatal alicerçado na ética comunitária por regras informais de conduta que têm como único argumento a eficiência econômica ${ }^{45}$.

Diante dessa situação, a soberania econômica resta prejudicada, verificando-se que não é mais possível ao Estado questionar as regras fundamentais para a boa governabilidade. Dessa maneira, a democracia certamente resta afetada: as escolhas não condizentes com os interesses do mercado global podem ser por ele punidas e propostas de desenvolvimento não condizentes são mal vistas pela comunidade internacional.

Mas quais os limites para o desenvolvimento? O simples interesse econômico atende à expectação social?

Certamente não.

Cada vez mais se vê, dentre outros, a fome, a desigualdade social, a diversas formas de exploração do meio ambiente, o retorno à escravidão em situações

\footnotetext{
${ }^{45}$ Para maiores aprofundamentos sobre a questão ética mencionada, sugere-se a obra: CORTINA, Adela. Ética transnacional e cidade cosmopolita. In: MERLE, Jean-Cristophe; MOREIRA, Luiz.

Direito e Legitimidade. São Paulo: Landy, 2003.
} 
PETERMANN, Vânia; FARIAS, Paulo Marcos de. Entre a soberania estatal e a economia: a reinvenção do judiciário como poder na atual fase da globalização. Revista Eletrônica Direito e Política, Programa de Pós-Graduação Stricto Sensu em Ciência Jurídica da UNIVALI, Itajaí, v.10, n.2, $1^{\circ}$ quadrimestre de 2015. Disponível em: www.univali.br/direitoepolitica - ISSN 1980-7791.

desumanas de trabalho na puta de reinvindicações. A sociedade se desenvolve economicamente, mas não em seus laços de compreensão ao próximo e solidariedade. Vale lembrar que, como mecanismo de propaganda, muitas das grandes corporações invocam essas questões por meio de projetos e compromissos, de modo a disseminar uma imagem de comprometimento social. Nem, sempre, todavia, essa é a real finalidade dessa imagem que se pretende refletir, pois o interesse revela-se em benefícios fiscais e na projeção de imagem positiva aos olhos da sociedade ${ }^{46}$.

Ademais, deve ficar claro que não se prega a baixa renda como fator decisório, mas sim como componente a justificar a incapacidade de autosuficiência da economia para resolver os problemas oriundos dos direitos sociais não efetivados. Portanto, como recomenda a leitura de Amartya SEN:

\begin{abstract}
Embora valha a pena ressaltar essas relações entre a pobreza de renda e pobreza de capacidades, também é importante não perder de vista o fato fundamental de que a redução da pobreza de renda não pode, em si, ser motivação suprema de políticas de combate à pobreza. [...] Acontece que o aumento das capacidades humanas também tende a andar junto com a expansão das produtividades e do poder de auferir renda. Essa conexão estabelece um importante encadeamento indireto mediante o qual um aumento de capacitação ajuda direta e indiretamente a enriquecer a vida humana e tornar as privações humanas mais raras e menos pungentes. As relações instrumentais, por mais importantes que sejam, não podem substituir a necessidade de uma compreensão básica da natureza e das características de pobreza. ${ }^{47}$
\end{abstract}

Nessa contextura apresentada, extrai-se que economia e Estado encontram seu ponto de equilíbrio na imperiosa efetivação dos direitos fundamentais, e, conforme Norberto BOBBIO:

A efetivação de uma maior proteção dos direitos do homem está ligada ao desenvolvimento global da civilização

\footnotetext{
${ }^{46}$ Para aprofundar o estudo sobre a questão, indica-se o filme "A Corporação" ou "The Corporation" no qual esses temas são abordados e os fundamentos dos argumentações indicados. Disponível em: <https://www.youtube.com/watch?v=ZxOf_8FKMrY>. Acesso em 20 abr. 2014.

${ }^{47}$ SEN, Amartya. Desenvolvimento como liberdade. Tradução: Laura Teixeira Motta. São Paulo: Companhia das Letras, 7 a reimpressão. 2008, p. 115. Título original: Development as freedom.
} 
PETERMANN, Vânia; FARIAS, Paulo Marcos de. Entre a soberania estatal e a economia: a reinvenção do judiciário como poder na atual fase da globalização. Revista Eletrônica Direito e Política, Programa de Pós-Graduação Stricto Sensu em Ciência Jurídica da UNIVALI, Itajaí, v.10, n.2, $1^{\circ}$ quadrimestre de 2015. Disponível em: www.univali.br/direitoepolitica - ISSN 1980-7791.

humana. É um problema que não pode ser isolado, sob pena, não digo de não resolvê-lo, mas de sequer compreendê-lo em sua real dimensão. Quem o isola já o perdeu. Não se pode pôr o problema dos direitos do homem abstraindo-o dos dois grandes problemas de nosso tempo, que são os problemas da guerra e da miséria, do absurdo contraste entre o excesso de potência que criou as condições para uma guerra exterminadora e o excesso de impotência que condena grandes massas humanas à fome. Só nesse contexto é que podemos nos aproximar do problema dos direitos com senso de realismo ${ }^{48}$.

E nesse caminho, para os casos de violação e descumprimento, inclusive no que respeita ao aspecto coercitivo, dá-se ao Poder Judiciário o grande desafio de decidir questões que afrontem aos direitos humanos, sem perder de mira oportunidades de desenvolvimento social que podem erradicar a pobreza e incluir a nação no mercado internacional.

A este respeito, não pode o Judiciário fechar os olhos à inoperância das demais funções estatais, silentes ou coniventes aos interesses econômicos de solução rápida, deixando seus povos a toda má sorte da miséria.

No caso brasileiro, como mencionado, situação que se repete nos países de modernidade tardia, o descaso com a população, com seus direitos mais básicos, por parte do Executivo e do Legislativo, têm feito com que o Judiciário assumisse mais intensamente sua responsabilidade por realizar plenamente a Constituição. O fundamento está na postergação, no adiamento indefinido da realização da Constituição, ao mesmo tempo em que há recordes de arrecadação tributária e grandes escândalos de corrupção, desvio e mau uso dos recursos públicos ${ }^{49}$.

Dada à previsão no texto das constituições na condição de direitos fundamentais, pois, é dever do Estado agir. ${ }^{50}$

\footnotetext{
${ }^{48}$ BOBBIO, Norberto. Tradução: Carlos Nelson Coutinho. A Era dos direitos. 13a tiragem. São Paulo: 2004, p. 44.

${ }^{49}$ TAVARES, André Ramos. Justiça Constitucional e Direitos sociais no Brasil. In: FRANCISCO, José Carlos (Coord.). Neoconstitucionalismo e atividade jurisdicional: do passivismo ao ativismo judicial, p. 150.

${ }^{50}$ Não se afirma, aqui, que a solução aos efeitos nefastos do desenvolvimento econômico egoístico reside só no Estado. Claro que isso depende também de ações da sociedade civil. Mas no âmbito deste estudo toca-se à quota parte do Estado, que, por ser o guardião dos direitos fundamentais
} 
PETERMANN, Vânia; FARIAS, Paulo Marcos de. Entre a soberania estatal e a economia: a reinvenção do judiciário como poder na atual fase da globalização. Revista Eletrônica Direito e Política, Programa de Pós-Graduação Stricto Sensu em Ciência Jurídica da UNIVALI, Itajaí, v.10, n.2, $1^{\circ}$ quadrimestre de 2015. Disponível em: www.univali.br/direitoepolitica - ISSN 1980-7791.

Nesse caminho, pondera-se:

O grau de certeza nesta atuação traduz-se em boa medida no grau de democracia. Judiciário e democracia estão tão intrinsecamente relacionados que se pode afirmar que quanto maior o grau de certeza na atuação do Judiciário, no sentido de garantir a soberania popular e o respeito integral aos direitos fundamentais, maiores serão os graus de democracia alcançados por uma determinada sociedade ${ }^{51}$.

Daí porque se entende que a nova contextura global exaustivamente declinada faz desse século o século do Judiciário enquanto Poder, como instituição estatal incumbida de, mediante a salvaguarda dos direitos fundamentais Constituições, equilibrar e ponderar duas das maiores forças: a economia e o Estado.

\section{CONSIDERAÇÕES FINAIS}

O progresso é um caminho desejável e buscado pela humanidade desde os tempos mais remotos.

A globalização adveio nesse processo de desenvolvimento, e representa um grande marco, o qual alterou substancialmente o modo de ser, agir, pensar, das pessoas, tendo em vista a redução das distâncias e barreiras. A internet que também é produto desse fenômeno, por exemplo, permite que o mundo todo acompanhe, em tempo real, desde a final do jogo da copa do mundo, a posse de chefe de Estado ou a derrocada de ditador. Proporciona, ainda, a disseminação de ideias, padrões, consumo, dentre outros.

E em meio a essas transformações, verificou-se que a globalização potencializou o poder da economia e consequentemente de empresas, corporações, uma vez que proporcionou ao capital o atingimento de "vida própria", para o além do Ente estatal.

constitucionalmente resguardados, tem o dever de efetivá-los, inclusive na esfera das deliberações do Terceiro Poder (o Judiciário).

${ }^{51}$ SADEK, Maria Tereza Aina. Poder Judiciário e democracia: uma visita a "O Poder Judiciário no Regime Democrático". In: BENEVIDES, Maria Victoria de Mesquita. BERCOVICI, Gilberto. MELO, Claudineu de (Orgs.). Direitos Humanos, Democracia e República: Homenagem a Fábio Konder Comparato. São Paulo: Quartier Latin, 2009. p. 714 
PETERMANN, Vânia; FARIAS, Paulo Marcos de. Entre a soberania estatal e a economia: a reinvenção do judiciário como poder na atual fase da globalização. Revista Eletrônica Direito e Política, Programa de Pós-Graduação Stricto Sensu em Ciência Jurídica da UNIVALI, Itajaí, v.10, n.2, $1^{\circ}$ quadrimestre de 2015. Disponível em: www.univali.br/direitoepolitica - ISSN 1980-7791.

Nesse caminho, então, se num primeiro o Estado Nacional se apresentou como aliado para a expansão econômica, num contexto global passou a ser entrave, vez que impõe restrições, obrigações, controle para salvaguarda do direito interno. E dado agigantamento da economia, observou-se a existência de ideários (neo)liberalistas, minimalistas, sob o argumento do desenvolvimento, do progresso.

Ocorre que paralelamente a essa expansão econômica, a sociedade experimentou também a consagração de direitos humanos, inicialmente como limitadores à interferência estatal (liberdade negativa), e após como instrumental de obrigações mínimas de cunho prestacional, necessárias para uma existência digna.

Esse sistema protetivo, em que pese possua eficácia vertical, encontra aplicação também no plano horizontal. Assim, se de um lado a economia pode levar ao progresso, este não pode justificar produção de violência, exploração, ou seja, não autoriza a violação à dignidade humana.

E é neste ponto que se vislumbrou a essencialidade do Estado, em que pese as alterações também por este sofridas na Era da globalização, inclusive em seus elementos básicos, como a soberania. Assim, se existem problemas, desafios, objetivos que suplantam as fronteiras e que demandam atuação conjunta, seja sob a égide de blocos econômicos, seja por organismos internacionais, a imperiosidade da realização dos direitos humanos mantém viva a necessidade do Estado Constitucional de Direito.

Como visto, a história revela que a sociedade se formou e foi se desenvolvendo com o objetivo de melhorar as condições de vida dos indivíduos, sendo o Estado Material de Direito fruto dessa busca. Logo, diante de todo o caminho já percorrido e dos anseios de superação da miséria, das guerras, das explorações, verificadas hodiernamente não só no discurso, mas também nas exigências levadas aos órgãos/instituições dirigentes das mais variadas formas (protestos, ações judiciais, pleitos administrativos, etc), não se pode admitir qualquer retrocesso. 
PETERMANN, Vânia; FARIAS, Paulo Marcos de. Entre a soberania estatal e a economia: a reinvenção do judiciário como poder na atual fase da globalização. Revista Eletrônica Direito e Política, Programa de Pós-Graduação Stricto Sensu em Ciência Jurídica da UNIVALI, Itajaí, v.10, n.2, $1^{\circ}$ quadrimestre de 2015. Disponível em: www.univali.br/direitoepolitica - ISSN 1980-7791.

Considerando que o Judiciário é a instituição incumbida da salvaguarda e da concretização dos Direitos Fundamentais, constatou-se que emerge, na atual conjuntura, como Poder na era da globalização. Isso porque na medida em que seu dever maior, como guardião da Constituição é, em suma, a defesa da dignidade da pessoa humana, núcleo fundamental dos direitos humanos, o Judiciário traz em si a possibilidade de equilibrar política e economia, proporcionando o progresso sem esquecer-se da origem, do motivo e do destino de tudo o que existe e/ou é criado em decorrência dele: o ser humano.

\section{REFERÊNCIAS DAS FONTES CITADAS}

AZAMBUJA, Darcy. Teoria Geral do Estado. Rio de Janeiro: Globo, 1969.

AGUILLAR, Fernando Herren. Direito econômico e globalização. In: Direito Global. Coordenadores: SUNDFELD, Carlos Ari, VIEIRA, Oscar Vilhena. São Paulo: Max Limonad, 1999.

BOBBIO, Norberto. Tradução de Carlos Nelson Coutinho. A era dos direitos. Rio de Janeiro: Elsevier, 2004. Título original: L'età dei Diritti.

; MATTEUCCI, Nicola, PASQUINO, Gianfranco. Tradução de Carmen C, Varriale et ai. Dicionário de Política. V. I e II. Brasília: UNB, $13^{a}$ ed. $3^{a}$ reimpressão, 2009.Título original: Dizionario di política.

BRASIL. Jornal o Globo. Disponível em http://g1.globo.com/economia/noticia/2014/08/argentina-acusa-juiz-americanode-impor-condicoes-ao-congresso.html>, acesso em 28/08/2014.

Governo Federal. Legislação Federal. Disponível em http://www.planalto.gov.br/ccivil_03/decreto/1930-1949/D1570.htm. Consulta em 29 ago 2014.

CAPPELLETTI, Mauro. Juízes Legisladores? Porto Alegre: Sérgio Anônio Fabris Editor, 1993. Título original: Giudici Legislatori?

CARVALHO, Morgana Bellazzi de Oliveira. A globalização e os desafios do Poder Judiciário no século XXI em prol da realização do bem-estar e do desenvolvimento. In: CONGRESSO NACIONAL DO CONPEDI, XVIII, 2009, São Paulo, Anais. Disponível em: <http://www.publicadireito.com.br/conpedi/manaus/arquivos/Anais/sao_paulo/2 072.pdf>. Acesso em: 20 jul. 2014.

COELHO, Edihermes Marques. Os direitos fundamentais em face da globalização de mercados e o garantismo como referência jurídica 
PETERMANN, Vânia; FARIAS, Paulo Marcos de. Entre a soberania estatal e a economia: a reinvenção do judiciário como poder na atual fase da globalização. Revista Eletrônica Direito e Política, Programa de Pós-Graduação Stricto Sensu em Ciência Jurídica da UNIVALI, Itajaí, v.10, n.2, $1^{\circ}$ quadrimestre de 2015. Disponível em: www.univali.br/direitoepolitica - ISSN 1980-7791.

necessária. Tese de doutoramento. Universidade Federal de Santa Catarina. 2002.247 p. 24 Disponível em: <https://repositorio.ufsc.br/handle/123456789/82613>. Acesso em 20 de ago de 2014.

CORTINA, Adela. Ética transnacional e cidade cosmopolita. In: MERLE, JeanCristophe; MOREIRA, Luiz. Direito e Legitimidade. São Paulo: Landy, 2003.

GARAPON, Antoine.Tradução de Maria Luiza de Carvalho. 0 juiz e a democracia: o guardião das promessas. 2 ed. Rio de Janeiro: Revan, 2001. Título original: Le gardien dess promesses.

GIDDENS, Anthony. Tradução: Álvaro Hattner. Para além da esquerda e da direita. O futuro da política radical. São Paulo: UNESP, 1996. Título original: Beyond Left and Right: TheFuture of Radical Politics.

GUERRA, Sidney. A quarta onda globalizante e os desafios para o direito internacional. In Revista da Faculdade de Direito de Campos, Rio de Janeiro, Ano IV, n. 4 e Ano V, n. 5, 2003-2004. p. 341 a 357. Disponível em http://fdc.br/Arquivos/Mestrado/Revistas/Revista04e05/Docente/17.pdf Consulta em 29 de ago de 2014.

HOBBES, Thomas. Leviatã ou a matéria, forma e poder de um estado eclesiástico e civil. São Paulo: Ícone, 2008.

MARTY, Mireille DELMAS. Tradução: Maria Ermantina de Almeida Prado Galvão. Por um direito comum. Martins Fontes: São Paulo, 2004. Título no original: Pour um droit commun.

MATIAS, Eduardo Felipe. A Humanidade e suas fronteiras. São Paulo: Paz e Terra, 2005.

MORAIS, José Luis Bolzan de. Diretos humanos, Estado e globalização. Direitos humanos e globalização: fundamentos e possibilidades desde a teoria crítica. Org. David Sánchez Rúbio, Joaquín Herrera Flores, Salo de Carvalho. - 2. ed. Dados eletrônicos. - Porto Alegre : EDIPUCRS, 2010. 578 p. Disponível em http://www.pucrs.br/edipucrs/direitoshumanos.pdf. p. 131-132. Consulta em 29 de ago 2013.

ROBERTSON, Roland. Mapeamento da condição global: globalização como conceito central. In FEATHERSTONE, Mike (coord.) Cultura global nacionalismo, globalização e modernidade. trad. de Attílio Brunetta. Rio de Janeiro: Vozes, 1994.

ROSA, Alexandre Morais da; LINHARES, José Manuel Aroso. Diálogos com a Law \& Economics. Rio de Janeiro: Lumen Juris Editora, 2009.

SADEK, Maria Tereza Aina. Poder Judiciário e democracia: uma visita a "O Poder Judiciário no Regime Democrático". In: BENEVIDES, Maria Victoria de Mesquita. BERCOVICI, Gilberto. MELO, Claudineu de (Orgs.). Direitos Humanos, 
PETERMANN, Vânia; FARIAS, Paulo Marcos de. Entre a soberania estatal e a economia: a reinvenção do judiciário como poder na atual fase da globalização. Revista Eletrônica Direito e Política, Programa de Pós-Graduação Stricto Sensu em Ciência Jurídica da UNIVALI, Itajaí, v.10, n.2, $1^{\circ}$ quadrimestre de 2015. Disponível em: www.univali.br/direitoepolitica - ISSN 1980-7791.

Democracia e República: Homenagem a Fábio Konder Comparato. São Paulo: Quartier Latin, 2009.

SANTOS, Boaventura Sousa. Processos da globalização. p. 25-94. In: SANTOS, Boaventura (Org.). A globalização e as ciências sociais. 3. ed. São Paulo: Cortez, 2005.

- Os processos da globalização. Disponível em <http://www.eurozine.com/articles/2002-08-22-santos-pt.html>. Acesso em: 29 ago de 2013. Sem paginação.

Pela mão de Alice. O social e o político na pós-modernidade. 2 ed. Cortez: São Paulo, 1996.

SARLET, Ingo Wolfgang. A eficácia dos Direitos Fundamentais: uma teoria geral dos direitos fundamentais na perspectiva constitucional. 11 ed. rev e atual. Porto Alegre: Livraria do Advogado Editora, 2012.

SEN, Amartya. Desenvolvimento como liberdade. São Paulo: Companhia das Letras, 2000.

TAVARES, André Ramos. Justiça Constitucional e Direitos sociais no Brasil. In: FRANCISCO, José Carlos (Coord.). Neoconstitucionalismo e atividade jurisdicional: do passivismo ao ativismo judicial. Belo Horizonte-MG: Del Rey Editora, 2012.

WEBER, Max. Tradução de Johannes Winckelmann. Economia e Sociedade. Vol. 1. Brasília: UNB, 1972. Título original: Wirtschaft und Gesellschaft.

Submetido em: Março/2015

Aprovado em: Abril/2015 